\title{
A FORMAÇÃO/PRODUÇÃO DA MERCADORIA FORÇA DE TRABALHO DOPROFESSOR: UMA ANÁLISE À LUZ DO MATERIALISMO HISTÓRICO
}

\section{ROGÉRIO PAES DE OLIVEIRA ${ }^{1}$, ALISSON SLIDER DO NASCIMENTO DE PAULA $^{2}$ E FREDERICO JORGE FERREIRA COSTA ${ }^{3}$}

RESUMO: O pressente estudo possui como objetivo a tentativa de desvelar como a força de trabalho do professor está inserida na lógica global do capital como mercadoria, em uma conjuntura na qual os cursos de formação de professores aumentaram, consideravelmente, suas matrículas, sobretudo os cursos de Educação a Distância $(\mathrm{EaD})$ nas Instituições de Ensino Superior privadas. A mercadoria força de trabalho do professor está inserida na lógica do modo de produção capitalista e, portanto, na mesma lógica do valor. Assim sendo, quanto menor o tempo de produção da sua força de trabalho, menor será o seu valor e menor será o seu preço. Concernente aos procedimentos metodológicos, optou-se por um estudo de caráter bibliográfico na qual os pressupostos teórico-metodológicos do materialismo histórico serão referência matricial. Considerou-se que estando o professor desprovido dos meios de produção, necessita vender sua força de trabalho para manter-se vivo nessa sociabilidade hodierna, no contexto da expansão dos cursos de licenciatura e diminuição do tempo de produção da mercadoria força de trabalho do professor, com conseguinte diminuição dos salários.

PALAVRAS-CHAVE: Mercadoria Força de Trabalho; Professor; Materialismo Histórico.

ABSTRACT: The present study aims at the attempt to unveil how the workforce of the teacher is inserted in the global logic of capital as a commodity. Between 1991 and 2002 teacher training courses have increased considerably, particularly Distance Education (EaD) courses in private higher education institutions, making bachelors as the top-level course that most put the workforce on the market ready to be sold. The commodity of the teacher's workforce is embedded in the logic of the capitalist mode of production and, therefore, is embedded in the same logic of value and, therefore, the shorter the production time of its labor power, lower its value and lower his price. Concerning the methodological procedures, a bibliographical study was chosen in which the theoretical-methodological assumptions of historical materialism will be the matrix reference. It was considered that, since the teacher is

\footnotetext{
${ }^{1}$ Professor da Educação Básica/ Santana do Cariri-CE. Mestre no Programa de pós-graduação em Educação na Universidade Estadual do Ceará (UECE). Membro do Grupo de Pesquisa Ontologia do Ser Social, História, Educação e Emancipação (GPOSSHE). Email:rogerio.paes@hotmail.com.

2 Professor do curso de Educação Física do Centro Universitário INTA (UNINTA). Doutorando em Educação pela Universidade Estadual do Ceará (UECE). Membro do Grupo de Pesquisa Ontologia do Ser Social, História, Educação e Emancipação (GPOSSHE). E-mail: alisson.slider@yahoo.com.

3 Professor Adjunto em Educação da Universidade Estadual do Ceará (UECE). Doutor em Educação pela Universidade Federal do Ceará (UFC). Coordenador do Grupo de Pesquisa Ontologia do Ser Social, História, Educação e Emancipação (GPOSSHE). E-mail:Frederico.costa@uece.br.
} 
deprived of the means of production, he needs to sell his work force to keep himself alive in today's sociability, in the context of the expansion of the licentiate courses and decrease of the time of production of the teacher-wages.

KEYWORDS: Labor Force Merchandise; Teacher; Historical Materialism.

É comum a presença de slogans em propagandas de movimentos sindicais e classistas de professores que tragam frases como: "respeito aos professores", "professor não é mercadoria”, “valorização já!”, “educação não é mercadoria”, entre outras. Embora agitação e propaganda utilizem frases dessa natureza, não há uma aprofundada contextualização e um debate acerca de seu real significado, sobretudo por estarmos inseridos em uma sociedade regida pelo sistema sociometabólico do capital em que todas as produções humanas tendem a tornar-se mercadorias.

O objetivo desse trabalho é desvelar como a força de trabalho do professor está inserida na lógica global do capital como mercadoria. Essas tendências apontadas por Karl Marx na obra O'Capital (2011) serão, portanto, bases teóricas do presente ensaio. Para Marx (2011), a mercadoria na sociedade capitalista, além de ser um produto de consumo das necessidades humanas, é também veículo de acumulação de capital, podendo ser, em seu caso mais especial - a mercadoria força de trabalho -, necessária para produção e reprodução do capital.

A produção e expansão do capital necessita de um processo de produção de mercadorias com possibilidades produtivas em grande escala num curto períodos de tempo, tendência que também pode ser verificada nos processos produtivos de capital que não estejam diretamente articulados com a relação homem x natureza. Nessa acepção, a formação de professores no Brasil tem sido tratada como um grande business, a partir da expansão mercantilizada dos cursos de licenciatura tanto pelas Instituições de Educação Superior (IES) públicas como privadas.

Com o aumento do apetite do sistema sóciometabólico do capital através da sua acumulação, a própria expansão no ensino superior, da forma como está sendo implementada, contribui para a diminuição do valor da força de trabalho do professor, que vem sendo formada de forma aligeirada, ou seja, uma produção em massa de graduados em licenciatura nas diferentes áreas para ocupar os poucos espaços de trabalho disponíveis. Sendo o valor $o$ tempo socialmente médio necessário para produção e reprodução da força de trabalho, a "fábrica de diplomas" acaba por diminuir o tempo de formação dos professores. Nesse sentido, levantamos hipóteses, a saber: i) dá-se uma valorização do valor pela compra e venda 
da mercadoria ensino superior; ii) ocorre uma diminuição do tempo médio necessário para produção da mercadoria força de trabalho professor.

$\mathrm{Na}$ tentativa de desvelar esse movimento de mercadorização da força de trabalho do professor, os pressupostos teórico-metodológicos do materialismo histórico serão referenciais matriciais para elaboração deste estudo de caráter bibliográfico.

Marx, na perspectiva teórico-metodológica do materialismo histórico, preconizou a necessidade da investigação detalhada do objeto a ser estudado. Diferencia, no Posfácio da Segunda Edição d' O Capital, escrito em 1873, o método de investigação do método formal de exposição. Para ele, a investigação é o momento onde o sujeito se apodera das determinações do objeto que aparece como pobre em determinações e vai se enriquecendo durante a pesquisa. É apenas após essa processualidade que o sujeito pode, de forma mais adequada, expor o movimento do real. "Se isto se consegue, ficará espelhada, no plano ideal, a vida da realidade pesquisada, o que pode dar a impressão de uma construção a priori" (MARX, 2011, p. 28).

É com base nessa perspectiva que o referido trabalho está organizado em três seções. 1) A formação do professor na sociedade do capital: impasses atuais, possui como objetivo debater a conjuntura na qual se encontra a formação dos professores no contexto da expansão mercantilizada no ensino superior, demostrando a íntima ligação desse movimento com a tendência global do modo de produção capitalista de diminuir o valor das mercadorias; 2) $O$ professor e sua mercadoria força de trabalho objetiva explicar o que é a força de trabalho, como se produz, demostrando que a mercadoria vendida pelo professor é sua força de trabalho; 3) A compra e venda da força de trabalho do professor: a produção de mais valia objetiva demostrar que o "enigma" da produção de mais valia está na compra e venda da força de trabalho e, portanto, o professor produtor de mais valia é aquele que vende sua força de trabalho a um capitalista que suga suas capacidades físicas e espirituais durante sua jornada de trabalho, produzindo um excedente e expropriando-o privadamente.

\section{A formação do professor na sociedade do capital: impasses atuais}

De acordo com a Lei nº 9.394 de 1996 - Lei de Diretrizes e Bases da Educação Nacional (LDBEN) -, em seu artigo $\mathrm{n}^{0}$. 62, os professores necessitam, para exercer sua profissão, de uma titulação mínima de nível superior em cursos de graduação com a formação na modalidade de licenciatura plena. 
A Formação de professores no Brasil tem sido tratada como um grande comércio através da expansão das vagas discentes nas IES, mormente nas privadas, diluindo as fronteiras entre o público e o privado a partir da operacionalidade das políticas educacionais, além da expansão crescente destas instituições; dá-se o aligeiramento da formação que se efetua com instituições que desrespeitam o trato didático-pedagógico da formação, descaracterizando o elo indissociável entre ensino, pesquisa e extensão, ao mesmo tempo em que as instituições privadas ganham destaque com políticas públicas direcionadas para a sua processualidade, que se realiza a partir da oferta de vagas tidas como "públicas", através de programas como o Programa de Financiamento Estudantil (FIES) e o Programa Universidade para Todos (PROUNI). No que tange este segundo, Costa afirma que:

R\$ 3.329.825.169,00 (três bilhões, trezentos e vinte e nove milhões, oitocentos e vinte e cinco mil e sessenta e nove Reais) é o valor da isenção fiscal decorrente do PROUNI, o que não foi arrecadado pela União a contar de 2006 a 2012. Esta isenção físcal é o dispensado das IES privadas, parceiras do PROUNI, gerado pela não arrecadação das contribuições do IRPJ [Imposto de Renda para Pessoas Jurídicas], CSLL [Contribuição Social sobre o Lucro Líquido], CONFINS [Contribuição para Financiamento da Seguridade Social], PIS [Programas de Integração Social] e $20 \%$ de desconto na Contribuição previdenciária da Cota Patronal. A título de conhecimento, para ter uma ideia quanto à dimensão do montante da isenção fiscal do PROUNI, segundo estudos da ANDIFES [Associação Nacional dos Dirigentes das Instituições Federais de Ensino Superior no Brasil] relatado em Andes [Sindicato Nacional dos Docentes das Instituições de Ensino Superior] (2004), a associação informa que R\$ 1.000.000.000,00 (um bilhão de Reais) seriam suficientes para dobrar o número de vagas existente nas IES federais (COSTA, 2013, p. 08).

Até o ano de 2016, o montante de recursos investidos ultrapassava os R\$ 4 bilhões, como foi noticiado por vários jornais eletrônicos baseados em dados da receita federal acerca da renúncia fiscal que o governo concede às IES privadas para abertura de vagas referentes ao Prouni. Concomitantemente, presenciamos os cortes nos custeios das universidades públicas sendo ameaçadas de fecharem suas portas, como é o caso das Universidade Estadual de Maringá, da Estadual do Rio de Janeiro, entre outras.

O Estado como representante da burguesia alimenta boa parte dos lucros dessas universidades/empresas, como podemos constatar com a renúncia fiscal, os incentivos de bolsas pelo FIES, além do proposital sucateamento das IES públicas. Estas, por seu turno, não contemplam nem $25 \%$ do número de matriculas no ensino superior. As $87,7 \%$ das IES privadas no Brasil, com a característica de seu corpo docente ser composto, predominantemente, por mestres, possuem "uma participação de 75,3\% (6.058.623) no total de matrículas de graduação. A rede pública, portanto, participa com 24,7\% (1.990.078)" (INEP, 2016, p. 5). 
Segundo Diniz-Pereira (2015), não se pode negar que no Brasil a formação acadêmicoprofissional de professores acontece, hoje, principalmente no ensino superior privado, especialmente, em "universidades-empresas"" e em faculdades isoladas e, de modo crescente, por meio de cursos a distância - a maioria deles também privados.

\begin{abstract}
No interior do país, em cidades pequenas e médias onde praticamente não há opções em termos de instituições públicas de ensino superior, predominam IES privadas de pequeno porte - as chamadas "faculdades isoladas" - que cobram mensalidades ainda mais baratas do que as tais "universidades de massa" e visam, principalmente, o "mercado" (sic) da classe D (DINIZ-PERREIRA, 2015, p. 276).
\end{abstract}

Há uma tendência na venda de cursos de educação superior em especial nas cidades de pequeno e médio porte. As pequenas faculdades-empresas dominam a oferta de vagas em cursos de educação superior, em especial em cursos de licenciatura.

Conforme os dados do censo da educação superior, divulgados em 2016, foram 1.520.494 matriculas nos cursos de licenciatura, nas quais 941.380 foram realizadas em IES privadas, ao passo que nas IES públicas foram realizadas 579.114 matrículas, o que demostra a validade da argumentação de Diniz-Pereira e sua constatação de que o professor vem sendo formado não só na lógica capitalista, mas predominantemente em universidades que buscam vender o ensino para extrair a mais valia.

Esse mercado em expansão na formação superior só não é maior do que o de EAD. Segundo Diniz-Pereira (2015), o mercado das EaDs teve um crescimento exponencial. Esse crescimento é tão avassalador que já representa um pouco mais de $18 \%$ do número de matrículas em todo o ensino superior, como se pode observar nos dados apresentados no Censo da Educação Superior divulgados pelo Inep 2016. Com isso, partindo para uma análise temporal acerca da evolução do crescimento no número de matrículas na graduação, constatamos que, em 2006, somente $4,2 \%$ das matrículas eram realizadas na modalidade EaD, chegando a 17,4\% em 2015 e, no último censo, 2016, a uma representação de $18,6 \%$ do número de matrículas nas IES brasileiras, representando, deste modo, um crescimento relativo da ordem dos $342,86 \%$ das matrículas na modalidade EaD.

Segundo dados do Censo da Educação Superior de 2014 divulgados, pelo INEP em 2015, as matrículas em cursos a distância são, na sua maioria, na rede privada e em de licenciatura. Outro dado interessante mostra o aumento dos cursos de licenciatura de 1991 até 2002. Em 1991, eram 2.512, sendo que, destes, 1.114 eram em IES pública e 1.398 em IES

\footnotetext{
${ }^{4}$ Termo utilizado pelo autor para referendar as IES privadas com fins lucrativos, em especial os cursos abertos em finais de semana de forma precária.
} 
privada, com um somatório de 103.875 formandos. Em 2002 os cursos já eram 5.880 , com 176.569 formandos. Em 2016 já representam 1.494.418 matrículas em cursos distância sendo oferecidos em sua maioria palas IES privadas (INEP, 2016). Diniz-Pereira (2015) contribui para essa compreensão:

A taxa de crescimento da EaD no Brasil, concentrada principalmente nas IES privadas que correspondem hoje a $74 \%$ do total -, foi de impressionantes $808 \%$ entre 2002 e 2007 . As matrículas nessa modalidade de ensino passaram de 31.712 , em 2002, para 838.125 , em 2009 (DINIZ-PEREIRA, 2015, p. 276).

Para o capitalista/empresário, pouco importa se a mercadoria que ele usa para mediar a relação do mercado e extrair mais valia é a educação ou uma fabrica de salsichas. Seu objetivo último é a produção e valorização do capital que só é possível com um movimento ininterrupto de circulação do dinheiro, transformando-o em capital. Como em todo processo de produção capitalista, o empresário busca a diminuição dos custos da produção da mercadoria, diminuindo o seus valores e o tempo socialmente necessário para produção da sua mercadoria. A mercadoria dos capitalistas da educação é a própria educação que, ao ser vendida, é imediatamente consumida na forma de ensino. Para produção dessa forma peculiar de mercadoria, o capitalista vai ao mercado, compra a força de trabalho dos técnicos, professores e demais funcionários para "produzirem" o curso a ser vendido. É evidente que essas forças de trabalho devem ter certo grau de qualificação e de apropriação do conhecimento socialmente produzido para serem ensinados nesses cursos, contudo, como forma de baratear essa mercadoria, o próprio professor da IES privada não necessita ter um elevado patamar de formação. É o que fica demostrado nos relatórios do Inep de 2016, no qual se evidencia que os professores doutores estão concentrados nas universidades públicas, enquanto nas IES privadas há uma predominância de mestres e especialistas.

Evidente que a titulação do professor não significa a garantia de qualidade de ensino, contudo esse debate torna-se secundário quando o que queremos demostrar é que a raiz da mercantilização da educação não está em oferecer cursos de menor qualidade, principalmente para a classe trabalhadora, e sim na lógica do capital valorizar incessantemente o valor.

Para o empresário da educação, sua principal motivação é o lucro. Se ele pode produzir sua mercadoria comprando forças de trabalho com menor valor, o empresário continuará a "ignorar" os doutores em suas instituições e, por conseguinte, exerce uma pressão nos salários dos professores com esse grau de formação. 
A produção/formação em larga escala dos professores pressiona para baixo os valores da força de trabalho do professor. O preço que paga-se ao professor não é explicado pela oferta e procura e sim pela lei do valor ${ }^{5}$.

Com a educação a distância, esse custo da produção cai ainda mais. Não é mais necessária uma sala com gastos de energia, água, funcionários de limpeza, inúmeros professores, possibilitando, assim, mais lucro ao capitalista/empresário. O capitalista aumenta sua taxa de lucro diminuindo os gastos para a produção de sua mercadoria, assim como aumenta a intensificação do trabalho do professor que vai ser o tutor de inúmeros estudantes a distância. Esse processo implica na fragilização da formação, aligeirando-a, como consequência do movimento essencial da tendência dos capitalistas, que é a apropriação e reprodução do capital. Assim como um produtor de automóveis altera a forma de produção de sua fábrica produzindo muito mais em um menor tempo e com a necessidade de contar com menos força de trabalho para isso, o empresário da educação, ao vender a mercadoria ensino à distância, até com preço menor do que o ensino presencial, diminuiu os custos para sua produção e diminuiu, principalmente, o número de professores/força de trabalho necessários no processo, mesmo que essa força de trabalho, na sociedade do capital, seja uma mercadoria necessária na produção do capital por ser a única capaz de produzir valor. Essas são tendências que podemos verificar na formação do professor que vem se caracterizando através da lógica crescente do setor empresarial, como uma formação privada, bem como a distância.

Os documentos apontam a exigência de um tempo maior para a formação individual do professor, que passou a ter, após a resolução do CNE no 02 de 2015, o tempo mínimo de 4 anos com aumento da carga horária mínima para de 3.200 horas (BRASIL, 2015). Contudo, esse tempo global diminui. Em última análise, o crescimento do número de matrículas nos cursos privados e em cursos a distâncias eo consequente aumento do número de força de trabalho professor disponível em um menor tempo tem como consequência um aligeiramento na formação, tornando as IES privadas verdadeiras fábricas de diplomas.

\footnotetext{
${ }^{5}$ Valor é o tempo socialmente médio necessário para produção de uma mercadoria. Quanto maior dispêndio de tempo médio, maior é o valor dessa mercadoria. Quanto menor o tempo médio, menor é o valor dela. Nesse sentido a lei que regula o modo de produção capitalista é a lei do valor descoberta por Marx (2011). Caso a produção de tomate caia por qualquer fator, o seu valor aumenta independente de sua procura, assim como uma produtividade enorme de milho diminui o seu valor mesmo que não seja bastante procurado.
} 


\section{O professor e sua mercadoria força de trabalho}

Possuindo a certificação necessária, o professor torna-se uma potencial força de trabalho a ser consumida. Como resultado, ele, enquanto trabalhador, possui a mesma mercadoria, e somente ela, dos demais homens e mulheres, sua força de trabalho. Nesse sentido, a aula do professor não constitui uma mercadoria produzida por ele, mas o mecanismo que ele possui para vender sua força de trabalho. Assim como o marceneiro produz objetos de madeira, o professor produz aula. No entanto, o que está sendo vendido pelo trabalhador professor e pelo trabalhador marceneiro não são os produtos advindos de sua atividade profissional e sim sua força de trabalho. "Por força de trabalho ou capacidade de trabalho compreendemos o conjunto das faculdades físicas e mentais existentes no corpo e na personalidade viva de um ser humano, as quais ele põe em ação toda vez que produz valoresde-uso de qualquer espécie" (MARX, 2011, p. 197).

O que o capitalista compra do trabalhador é sua capacidade de produzir algo que possa ser apropriado pelo capital. O capitalista compra as capacidades humanas do trabalhador, seja ele professor ou de qualquer outro ramo profissional. O que interessa para o capital é a capacidade humana do trabalhador convertida em trabalho produtivo ${ }^{6}$. O trabalho concreto capacidades corpóreas do trabalhador - do professor, sua especificidade, é o veículo para o trabalho abstrato - trabalho em geral como uma gosma que dilui todos os trabalhos concretos - e produtivo de mais valia.

Para que o professor possa estar à venda, ou seja, sua força de trabalho enquanto professor possa ser consumida, ele necessita ter características que a tornam uma mercadoria. Portanto, faz-se necessária uma compreensão do que é uma mercadoria para que se possa compreender a lógica do trabalho do professor enquanto força de trabalho a ser consumida.

A mercadoria é um objeto externo ao homem que satisfaz às diferentes necessidades humanas e, portanto, é uma coisa útil. Essa utilidade faz com que possua um valor de uso que está presente nela independentemente do quantum de trabalho empregado para obter sua utilidade. Marx (2011) descobre uma lógica que está por trás das fantasmagóricas relações de

\footnotetext{
${ }^{6}$ Trabalhar produtivamente no capitalismo significa produzir capital. A produção capitalista tem como finalidade a produção de mais valia ou mais valor. Na produção de qualquer que seja o produto, o capitalista compra as forças produtivas (meios de produção e força de trabalho) para colocar em movimento a produção. Nas palavras de Marx: "Para trabalhar produtivamente não é mais necessário executar uma tarefa de manipulação do objeto de trabalho; basta ser órgão do trabalhador coletivo" $(1985$, p. 584) e ainda: "Só é produtivo o trabalhador que produz mais valia para o capitalista, servindo assim a auto-expansão do capital” (MARX, 1985, p. 584).
} 
produção presentes no modo de produção capitalista. Dentre essas descobertas, o autor desenvolve a teoria do valor e desvela os mistérios do mecanismo mercantil e da mercadoria.

\begin{abstract}
A mercadoria é misteriosa por encobrir as características sociais do próprio trabalho dos homens, apresentando-as como características materiais e propriedades sociais inerentes aos produtos do trabalho, por ocultar, portanto, a relação social entre os trabalhos individuais dos produtores e o trabalho total, ao refleti-la como relação social existente, à margem deles, entre os produtos do seu próprio trabalho. Através dessa dissimulação, os produtos do trabalho se tornam mercadorias. [...] os produtos do cérebro humano parecem dotados de vida própria, figuras autônomas que mantém relações entre si e com os seres humanos. É o que ocorre com os produtos da mão humana, no mundo das mercadorias. Chamo a isso de fetichismo, que está sempre grudado aos produtos do trabalho, quando são gerados como mercadorias. É inseparável da produção de mercadorias (MARX, 2011, p. 94).
\end{abstract}

$\mathrm{Na}$ sociedade capitalista, esses valores de uso só existem na medida em que são veículos para os valores de troca, ou seja, para o professor estar à venda ele necessita ter um valor de uso para o comprador de sua força de trabalho. Seu valor de uso não deve servir para si próprio, contudo, deve tornar-se valor de troca. "O valor-de-uso só se realiza com a utilização ou o consumo. Os valores-de-uso constituem o conteúdo material da riqueza, qualquer que seja a forma social dela. [...] os valores-de-uso são, ao mesmo tempo, os veículos materiais do valor-de-troca" (MARX, 2011, p. 58).

O valor de troca da mercadoria só pode ser identificado na medida em que as mercadorias se trocam. Nesse sentido, uma mercadoria por si só não possui valor de troca. Existe a necessidade de se ter uma outra mercadoria que expresse o seu valor de troca. $\mathrm{Na}$ correlação 10 canetas $=10$ canetas, como são mercadorias da mesma natureza não se pode verificar o valor de troca da mercadoria. Já na correlação 1 caneta $=2$ lápis, o valor de troca da caneta está expresso em um quantum de lápis.

Se tomamos essas duas mercadorias, qualquer que seja a proporção de sua troca, é possível sempre expressá-la como um sinal de igualdade. Certa quantidade de canetas será sempre igual a certa quantidade de lápis.

A qualidade de canetas e de lápis, como valores de uso, só interessa para o seu possuidor que deseja troca-las, por dar uma utilidade a mercadoria e possibilitar como veículo do valor de troca. Enquanto valores de troca, deixam de ser valores de uso, e dialeticamente, necessitam ser valor de uso. "Como valores-de-uso, as mercadorias são, antes de mais nada, de qualidades diferentes; como valores de troca, só podem diferir na quantidade, não contendo, portanto, nenhum átomo de valor-de-uso" (MARX, 2011, p. 59).

Para Marx (2011), ao pôr de lado os valores úteis das mercadorias, abstrai-se também a qualidade dos trabalhos concretos nelas corporificados. Desvanece-se o caráter útil dos 
produtos do trabalho de forma que estes não diferem uns dos outros, mas reduzem-se a uma única forma de trabalho, o trabalho humano abstrato.

Nada deles resta, a não ser a mesma objetividade impalpável, a massa pura e simples do trabalho humano em geral, do dispêndio de força de trabalho humana, sem consideração pela forma como foi despendida. Esses produtos passam a representar apenas a força de trabalho humana gasta em sua produção, o trabalho humano que neles se armazenou. Como configuração dessa substância social que lhes é comum, são valores, valores-mercadorias (MARX, 2011, p. 60).

Nessa acepção, uma mercadoria só possui valor porque nela está corporificado um tempo de trabalho humano abstrato. O que determina a grandeza do valor, portanto, é a quantidade de trabalho socialmente necessária para produção de valores de uso.

Posto isso, pode-se afirmar que a força de trabalho do professor equivale a qualquer outra mercadoria de igual tempo socialmente necessário para sua produção, ou seja, mercadorias que contêm o mesmo tempo ou quantidade de trabalho corporificados na sua produção contêm igualmente o mesmo valor. Nas palavras de Marx: "O valor da força de trabalho é determinado, como o de qualquer outra mercadoria, pelo tempo de trabalho necessário à sua produção e, por consequência, à sua reprodução" (MARX, 2011, p. 200-201).

A força de trabalho do professor é valor de uso que satisfaz as necessidades dos donos de escolas particulares ou das políticas públicas de educação do Estado capitalista. Para ser produzida, necessita de um período/tempo de formação/produção. Contudo, essa mercadoria força de trabalho do professor necessita de outros valores de uso para satisfazer suas necessidades naturais. "Mas, para viver, precisa-se, antes de tudo, de comida, bebida, moradia, vestimenta e algumas coisas mais. O primeiro ato histórico é, pois, a produção dos meios para a satisfação dessas necessidades, a produção da própria vida material" (MARX; ENGELS, 2007, p. 33). Simplesmente para manterem-se vivos, os professores necessitam ir ao mercado com sua única mercadoria, a força de trabalho, e trocá-la por mercadorias que são necessárias diariamente para mantê-los vivos. O "vendedor da força de trabalho, como de qualquer outra mercadoria, realiza seu valor-de-troca e aliena seu valo-de-uso" (MARX, 2011, p.227). Essa troca de mercadorias é uma relação social e é medida por um equivalente geral. Ou seja, uma mercadoria que se equivalha, proporcionalmente, a todas as outras mercadorias existentes. Essa função é desempenhada, nos dias de hoje, pelo papel moeda dinheiro.

O comprador da força de trabalho do professor, compra essa mercadoria especial, assim como compra qualquer outra mercadoria disponível no mercado, pelo seu valor, tempo 
socialmente necessário para produzir uma mercadoria. Nas palavras de Marx (2011), "o possuidor do dinheiro pagou o valor diário da força de trabalho; pertence-lhe, portanto, o uso dela durante um dia, o trabalho de uma jornada inteira" (p. 227).

O dinheiro recebido pela força de trabalho do professor é correspondente ao seu valor $^{7}$. O professor mercantilizado recebe um quantum de dinheiro - salário - para materializar sua atividade profissional em uma aula.

\section{Compra e venda da força de trabalho do professor: a produção de mais valia}

Nesse momento, faremos um alerta ao leitor. Não é objetivo deste trabalho debater a precarização do trabalho docente. O que nos propomos é demostrar que o professor inserido na lógica global do capital, quando vende sua força de trabalho para uma instituição privada, acaba por inserir, como os demais trabalhadores, no ciclo reprodutivo de capital.

Só é produtor de mais-valia o professor que vende sua força de trabalho a um capitalista. O trabalho do professor na rede municipal, estadual e federal é improdutivo, sob o ponto de vista da mais-valia, mesmo sendo precário, desgastante. Contudo, o modelo de precarização dos demais professores, incluindo aspectos como o aumento de alunos em sala de aula e a redução de salários no ensino público, segue o modelo do trabalho produtor de capital e de mais-valia pelo professor da rede privada.

Desde 1990, no Brasil, conforme Oliveira (2006), os professores são atacados por um arrocho salarial ${ }^{8}$, por meio de políticas de contenção salarial e deterioração dos direitos trabalhistas.

Na passagem ao século XXI os salários docentes não tinham ainda recuperado as perdas sofridas nos regimes militares. Em 1997, o $1^{\circ}$ Censo do Professor do INEP mostrava que a média salarial nacional dos professores do Ensino Fundamental de $1^{\mathrm{a}}$ a $4^{\mathrm{a}}$ série variava entre $\mathrm{R} \$ 147,34$ para os que tinham até o $1^{\circ}$ grau e R $\$ 687,61$, para aqueles que tinham o $3^{\circ}$ grau completo ou mais. Em 2003, o mesmo INEP, por meio da "Sinopse do Censo dos Professores do Magistério da Educação Básica", indicava que a média salarial dos professores brasileiros de $1^{\mathrm{a}}$ a $4^{\mathrm{a}}$ série variava entre $\mathrm{R} \$ 300,00$, para aqueles que tinham o nível de escolaridade fundamental, até $\mathrm{R} \$ 644,00$, para aqueles com nível superior, curso de licenciatura, evidenciando que a média salarial dos professores não tinha se alterado significativamente, especialmente para aqueles com níveis de escolaridade mais altos [...]. Também a CNTE [Confederação dos Trabalhadores em Educação] denunciava em 2003, no "Relatório de Pesquisa sobre a Situação dos Trabalhadores(as) da Educação Básica", que de 1997 em diante não tinha havido praticamente crescimento dos salários dos professores

\footnotetext{
${ }^{7}$ Pressupomos nesse exemplo que o preço pago pelo capitalista pela utilização das capacidades humanas da força de trabalho equivale ao seu valor, enquanto sua expressão monetária.

8 "O limite último ou mínimo do valor da força de trabalho é determinado pelo valor da quantidade diária de mercadorias indispensável para que o portador da força de trabalho, o ser humano, possa continuar vivendo, ou seja, pelos meios de subsistência físicamente imprescindíveis. Se o preço da força de trabalho baixa a esse mínimo, baixa também seu valor, e ela só pode vegetar e atrofiar-se” (MARX, 2011, p. 203)
} 
brasileiros, sendo que a média salarial se situava na faixa de $\mathrm{R} \$ 600,00$, estando o Brasil em pior posição que a Indonésia à época da pesquisa (GARCIA; ANADON, 2009, p. 6869).

Como já foi citado nesse texto, quanto maior o número de formados em um mesmo período, menor será o seu valor. Um maior número de professores formados em um menor tempo pressiona para baixo os salários dos professores. A formação em escalas ampliadas em licenciatura, sobretudo advindas de cursos à distância, aumenta a produtividade da mercadoria força de trabalho do professor.

[...] quanto maior a produtividade do trabalho, tanto menor o tempo de trabalho requerido para produzir uma mercadoria e, quanto menor a quantidade de trabalho que nela se cristaliza, tanto menor seu valor. Inversamente, quanto menor a produtividade do trabalho, tanto maior o valor. A grandeza do valor de uma mercadoria varia na razão direta da quantidade e na inversa da produtividade do trabalho que nela se aplica (MARX, 2011, p. $62)$.

Para que o capital possa expandir, essa é uma tendência central. A busca incessante pela valorização do valor e uma tendencial queda na taxa de lucro só é possível pela diminuição do tempo necessário de produção, ou seja, pela queda do valor e, conseguinte incremento de ciência e tecnologia nos processos de trabalho. Marx destaca que "Qualquer que seja a mudança na produtividade, o mesmo trabalho, no mesmo espaço de tempo, fornece sempre a mesma magnitude de valor. Mas, no mesmo espaço de tempo, gera quantidades diferentes de valores-de-uso" (2011, p. 68).

Os professores produzem, antes de ser comercializados, valores de uso, assim como os bens que segundo Marx (2011), vêm ao mundo sob essa forma. Contudo, só se tornam mercadorias por sua duplicidade de, ao mesmo tempo, ser úteis e veículos de valor. A produção em longa escala de produtos como valores de uso não interessa ao capitalista. Nesse sentido, tendencialmente os valores de uso se tornam valores de troca e, portanto, mercadorias.

$\mathrm{Na}$ atividade de formação do professor, para dar valor e essa mercadoria em formação, não importa a qualidade desse processo, mas a quantidade de tempo, o que representa que ela possa ser trocada por um equivalente de mesmo valor e de qualidades diferentes ${ }^{9}$.

O comprador da força de trabalho do professor, ou seja, o possuidor do dinheiro, não irá pagar com outra mercadoria força de trabalho professor. Mercadorias com as mesmas

\footnotetext{
9 “A mercadoria é valor-de-uso ou objeto útil e 'valor'. Ela revela seu duplo caráter, o que ela é realmente, quando, como valor, dispõe de uma forma de manifestação própria, diferente da forma natural dela, a forma de valor-de-troca; e ela nunca possui essa forma, isoladamente considerada, mas apenas na relação de valor ou de troca com uma segunda mercadoria diferente" (MARX, 2011, p.82).
} 
qualidades não se trocam. Como a mercadoria do professor é sua força de trabalho, ela vai ser trocada pelo valor da soma dos seus meios de subsistência. Ou seja, o valor da mercadoria força de trabalho é o tempo socialmente necessário para que essa mercadoria permaneça viva e possa, novamente, vender sua força de trabalho.

O professor vai ao mercado oferecer sua única mercadoria, a força de trabalho, à espera de um comprador com dinheiro e meios de produção para colocar essa força de trabalho em movimento. O professor vende sua mercadoria para o dono de uma escola que o coloca no processo de trabalho de ministrar aulas. O produto do seu trabalho, sua aula, não lhe pertence, mas ao possuidor da escola e do dinheiro, que, por sua vez, vende esse valor de uso no mercado. O professor foi pago pelo seu valor, equivalente por equivalente. Contudo, no final de sua jornada de trabalho, produziu um valor excedente para o possuidor do dinheiro e da escola.

Nesse sentido, sua força de trabalho e o valor de uso produzido por sua atividade de trabalho assalariado foram mercantilizados, inserindo-se, portanto, na lógica global do capital.

Em síntese, como já afirmamos, só é produtivo de capital o professor da rede privada. Para o funcionamento do capitalismo é imprescindível que a propriedade seja privada. Ao vender sua força de trabalho, o professor põe em movimento uma cadeia de nexos causais, em decorrência do seu ato teleologicamente posto por suas capacidades e potencialidades humanas que não só contribuem para o aprendizado de crianças, adolescentes ou adultos. Ao final do seu processo, o comprador da força de trabalho adquiriu um montante maior do que o investido inicialmente, ou seja, o professor da rede privada produz uma quantidade de valor (tempo socialmente necessário) maior do que o seu próprio gerando, portanto, mais-valia.

\section{Considerações finais}

Buscou-se debater a situação na qual encontra-se inserido o professor, na lógica global do capitalismo que, por seu turno, tendencialmente, busca incessantemente tornar mercadorias todas as produções humanas. Com efeito, a formação de professores não escapa deste empreendimento. É notório o aumento de trabalhadores habilitados, ou seja, possuidores de diplomas em licenciatura no Brasil, decorrente dessa expansão mercantilizada da educação superior. Essa titulação/formação/produção é realizada em sua grande parcela nas instituições de ensino superior privadas e cada vez mais em cursos a distância, além da própria formação aligeirada. 
Essa lógica se insere e se articula com os elementos mais amplos da sociedade capitalista e sua ininterrupta busca por acumulação de capital. Na medida em que a expansão aumenta a produtividade da formação dos professores, o valor, ou seja, o tempo socialmente médio necessário para produção da força de trabalho do professor, cai. Nesse contexto, a lógica da expansão do ensino superior caminha para a tendência apontada por Marx (2011) que por um lado torna o elemento educação superior uma mercadoria vendida aos estudantes de licenciatura, por exemplo, para tornarem-se professores e possuir uma força de trabalho potencial, e por outro lado diminui o tempo socialmente médio necessário para produção da mercadoria força de trabalho do professor.

Tais estruturas e lógicas só podem desprender dessa mística e misteriosa ocultação da realidade, , por obras de homens e mulheres livres associados que planejam, controlam e regulam o seu intercâmbio material com a natureza de forma que a sociedade apresente as condições objetivas para esse desenvolvimento, o que aparenta ser um enorme fardo histórico para a atualidade.

\section{REFERÊNCIAS BIBLIOGRÁFICAS}

ANDES. A contrarreforma da educação superior: uma análise do andes-sn das principais iniciativas do governo de Lula da Silva. Caderno ANDES - Grupo de Trabalho de Política Educação. Brasília-DF, Agosto de 2004.

BRASIL. Conselho Nacional de Educação. Resolução CNE/CP n ${ }^{\circ}$ 02/2015, de $1^{\circ}$ de julho de 2015. Define as Diretrizes Curriculares Nacionais para a formação inicial em nível superior (cursos de licenciatura, cursos de formação pedagógica para graduados e cursos de segunda licenciatura) e para a formação continuada. Brasília, Diário Oficial [da] República Federativa do Brasil, seção 1, n. 124, p. 8-12, 02 de julho de 2015.

Lei no 9.394, de 20 de dezembro de 1996. Estabelece as diretrizes e bases da educação nacional. Diário Oficial da União, Brasília, DF, 20 dez. 1996.

COSTA, D. D. O PROUNI no contexto da expansão superior: dados preliminares sobre as condições do acesso decorrente do programa, no Brasil (2005-2010). Eixo 3 - Política e Gestão da Educação Superior. In: $26^{\circ}$ Simpósio Brasileiro de Política e Administração da Educação. Recife, 2013.

COSTA, F. J. F. A natureza ontológica do pensamento de Marx. Revista Eletrônica Arma da Crítica. Ano 1, n. 1, jan. 2009

DINIZ-PEREIRA, J. E. A situação atual dos cursos de licenciatura no Brasil frente à hegemonia da educação mercantil e empresarial. Revista Eletrônica de Educação, v. 9, n. 3, p. 273-280, 2015.

G1. Prouni deve custar R \$ 1,27 bilhões em 2016, maior valor desde sua criação. Disponível em: $\quad<$ http://g1.globo.com/educacao/noticia/2016/01/prouni-deve-custar-r-127-bilhao-em2016-maior-valor-desde-sua-criacao.html>. Acesso em: 20 de novembro de 2017. 
GARCIA, M. M. A.; ANADON, S. B. Reforma educacional, intensificação e autointensificação do trabalho docente. In: Educação \& Sociedade: Revista de Ciência da Educação. Vol. 30, n. 106, jan/abr. 2009. Campinas: 2009.

GAZETA DO POVO. Renuncia fiscal do Prouni sobe 166\%. Disponível em: $<$ http://www.gazetadopovo.com.br/vida-e-cidadania/renuncia-fiscal-ao-prouni-sobe-1669dnzyq1926zm61m2f6gdu0cwe>. Acesso em: 20 de novembro de 2017.

Instituto Nacional de Estudos e Pesquisas Educacionais Anísio Teixeira (INEP). Estatística dos professores no Brasil 2003. Brasília: O Instituto, 2003.

. Censo da Educação Superior 2014 - Notas Estatísticas. Brasília: O Instituto, 2014. . Censo da Educação Superior 2014 - Notas Estatísticas. Brasília: O Instituto, 2016.

MARX, Karl. $O$ capital: critica da economia política. Livro I. v. I. $28^{\circ}$ ed. Rio de Janeiro: Civilização Brasileira, 2011.

O capital: critica da economia política. Livro I. v. II. $4^{\circ}$ ed. São Paulo: DIFEL, 1985.

MARX, K.; ENGELS, F. O manifesto do partido comunista. São Paulo: Expressão popular, 2007

OLIVEIRA, D. A. A reestruturação do trabalho docente: precarização e flexibilização. Educação e Sociedade, Campinas, v. 25, n. 89, set/dez 2004. 